\title{
Numerical Analysis for Thermal Design of a Paraboloidal Solar Concentrating Collector
}

\author{
Hasnat $\mathrm{A}^{1^{*}}$, Ahmed $\mathrm{P}^{2}$, Rahman $\mathrm{M}^{2}$ and Khan $\mathrm{KA}^{1}$ \\ ${ }^{l}$ Department of Physics, ${ }^{2}$ Department of Mathematics, Jagannath University, Dhaka, Bangladesh.
}

[Received: June 02, Accepted: September 27, 2011]

\begin{abstract}
A paraboloidal solar concentrating collector in a non-planar configuration using reflecting materials of reflectance is 0.7 has been thermally designed and developed and at a 1metre focal distance in conjunction with a reverse flat plate absorber with black board paint (both selective and non selective coating) theoretically. To study optical and thermal performance tests like stagnation temperature ( $\left.\mathrm{T}_{\mathrm{ps}}\right)$, water temperature $\left(T_{w}\right)$, plate temperature $\left(T_{p}\right)$, thermal efficiency test $\left(X_{c}\right)$, optical efficiency test $\left(X_{o}\right)$, Heat transfer coefficient from surface to water (U), geometrical concentration ratio $(C)$ and overall heat loss coefficient $\left(U_{2}\right)$ has been studied. The concentrator is placed such that all incident parallel rays of light intercepted by the concentrator aperture are reflected to a common focus. In this case the concentrator parabolic in shape. This communication presents the thermal design analysis of a CR-system. The results of some typical numerical calculations are shown graphically and their significance is discussed.
\end{abstract}

Key words: Concentrating collector, mass flow rate, solar and thermal conversion.

\section{INTRODUCTION}

Paraboloidal solar concentrator is usually employed to receive the proper concentration of the solar flux on the linear absorbers. The analysis presented in this paper was used to study the performance characteristics of the paraboloidal concentrator in conjunction with a reverse flat plate (a rectangular channel) absorber ${ }^{[1,2]}$. It should however be noted that the analysis in general in nature where some assumptions were made to simplify the procedure. In the thermal analysis both the transient and steady state conditions were taken into consideration. This analysis would be applicable to any non-tracking or seasonally tracking concentrator with reverse flat plate absorber exposed to the concentrated flex ${ }^{[3,4]}$. The results computed on putting some typical values in the expressions obtained from the analysis are tabulated and presented graphically.

\section{MATERIALS AND METHODS}

Description of the prototype paraboloidal dish type concentrating collector/parabolic dish: The parabolic dish has undergone far less development than the parabolic trough. In this paper two prototype parabolic dishes are discussed: the Shenandoah dish and the JPL Parabolic Dish Concentrator. Both of these dishes presenting firstgeneration designs.

\section{Shenandoay Dish:}

The Shenandoah dish was designed for application to a solar thermal cogeneration project located at Shenandoah, GA ${ }^{[5,6]}$. The dish is designed to heat silicone oil in one pass to $400^{\prime} \mathrm{C}\left(750^{\circ} \mathrm{F}\right)$ with an inlet temperature of $260^{\circ} \mathrm{C}\left(500^{\circ} \mathrm{F}\right)$. The dish was designed by General Electric Corporation and was manufactured by Solar Kinetics, Inc. The $7 \mathrm{~m}$ diameter parabolic reflecting dish is formed of 21 aluminum petals, covered on one side with FEK-244 reflective film and then die-stamped to the correct contour. The petals are bolted to 21 supporting aluminum sheet metal ribs that are fastened to a fabricated steel central hub weldment. Design Many of the design tradeoffs discussed above for the prototype trough were also examined in the design of the Shenandoah dish. Dish diameter, for example, results from a tradeoff involving the desire to maximize dish diameter in order to decrease the amount of field piping in a given-size field. The difficulty (and thus expense) of constructing very large optical structures capable of withstanding the anticipated wind loads, however, limits the size of parabolic dishes. The central steel hub of the dish is supported at the declination points by a concrete counterweighted yoke structure. This yoke is held at an angle by two polar axis bearings that are, in turn, supported by a tubular steel tripod mount. The mount rests on a triangular base that is bolted to the tops of three concrete pier foundations that have been cast into the ground.

Tracking and Control - Drive about the polar axis is accomplished by rotation of the yoke structure by two $75 \mathrm{~W}$ i.e. 1/10 horsepower motor-driven jack screws in series, at the rate of 15 degrees per hour. A third jack screw of the same type pivots the dish on its yoke support points to provide for motion about the declination angle. 
A microprocessor-based control unit mounted on each concentrator provides tracking and safety commands (e.g., defocus during high winds or overheating). Coarse tracking is provided by a microprocessor ephemeris track. Fine tracking is provided by nulling the output of two pairs of fiber optics sensors located on the receiver aperture, one pair for each axis of rotation. A 17.5-mrad (1degree) angular motion microprocessor limit prevents wandering of the concentrator, due to extraneous reflections.

Receiver - The cavity receiver is designed to heat the heat-transfer fluid, Dow Corning Siltherm-800, to a maximum constant outlet temperature of $400^{\circ} \mathrm{C}^{[7,8]}$. Fluid supply and return lines are directed along a receiver support strut. Two sets of flexible hoses are required to compensate for differential movement of the dish receiver with respect to the fixed thermal distribution piping in the field. One flexible hose permits movement about the declination axis, whereas the other flexible hose permits the daily tracking movement of the dish about the polar axis. Concentrated light entering the cavity aperture strikes the tubes and is absorbed. Any light not absorbed on this first encounter with the tubing is reflected off the surface of the tube and strikes the coil of tubing in a different place, where it undergoes absorption again. Even if the absorptance of the tubing is only 0.6 , over 98 percent of the radiation will be absorbed after three reflections within the cavity ${ }^{[3.4]}$. The tested efficiency of the dish at its design conditions of $260^{\circ} \mathrm{C}\left(500^{\circ} \mathrm{F}\right)$ inlet, $400^{\circ} \mathrm{C}$ $\left(750^{\circ} \mathrm{F}\right.$ ) outlet is about $61 \%$ (Kinoshita, private communication). The efficiency of the dish is essentially constant with temperature as a result of the cavity receiver.

\section{JPL Parabolic Dish Concentrator-1}

The second parabolic dish discussed here is the JPL Parabolic Dish Concentrator-1 (PDC-1). This concentrator consists of a dish designed by the Space Division of the General Electric Company and a receiver-power conversion cycle module designed by the Aeronautics Division of Ford Aerospace and Communications Corporation. The power conversion system is designed to operate at $400^{\circ} \mathrm{C}$ and to provide electrical power to the power distribution grid of a small community.

Design - The $12 \mathrm{~m}$ diameter parabolic reflector surface consists of 12 gores (panels) made of fiberglass and balsa wood sandwich panels that are injection-molded to the correct contour. This lightweight construction was selected because of the very large aperture (12 m diameter) of the PDC- 1 . An aluminized polyester reflective film is then bonded to each panel. Each gore is essentially an arc segment $3 \mathrm{~m}$ at its widest point and approximately 6 $\mathrm{m}$ in length. The gores are attached to 12 frontbracing ribs, which supply support and alignment with minimal weight. Note that the diameter of this dish is considerably larger than that of the Shenandoah dish.

The support structure of the PDC-1 is designed for azimuth-elevation tracking. The dish is attached to a transverse semicircular truss and is pivoted at diametrically opposed points for a full 180-degree rotation. The truss is attached to the receiver at one end and to the counterweight at the other. The dish, truss, and pivots are supported by a lightweight space frame that rotates on wheels along a rolled I-beam circular steel track, which is supported from the ground by concrete piers. The receiver is supported by three arms and one end point of the semicircular truss.

Tracking and Control - The semicircular truss is rotated by use of a cable-drum arrangement. The cable rides in a channel in the semicircular truss from the receiver to the counterweight. Azimuth rotation is provided by a drive wheel that moves with the base along the circular track. The control system is a hybrid design similar in concept to that used with the parabolic trough system described earlier. A computed tracking angle is used for coarse tracking and fiber optic sensors located on the receiver are used for closed loop fine tracking. The fiber optic sensors are located at the receiver aperture and provide feedback information to the tracking system to center the reflected beam on the cavity aperture area. At the focus is a module containing a combined cavity receiver and Rankine power conversion cycle. The cavity receiver is a direct-heated, once-through monotube boiler that uses toluene at supercritical pressure. The cavity is formed by a cylindrical copper shell and backwall with stainless steel tubing brazed to the outside surface. This core is surrounded by lightweight refractory insulation, load-bearing struts and an outer case. The aperture plate is made of copper to provide long life by conducting and reradiating heat and stray concentrated flux away from the aperture lip.

Performance Comparison - A comparison of prototype parabolic dish and troughs with flat plate collectors is shown in Fig: 1. The below curves indicate the effects of operating temperature and solar radiation levels on the efficiency of the solar concentrating collector ${ }^{[9]}$. Of particular note is the low efficiency of the prototype parabolic dish which does not agree with the glass mirror reflector used. This is due to the low reflectance of the FEK-244 reflective plastic film used on the prototype dish. 


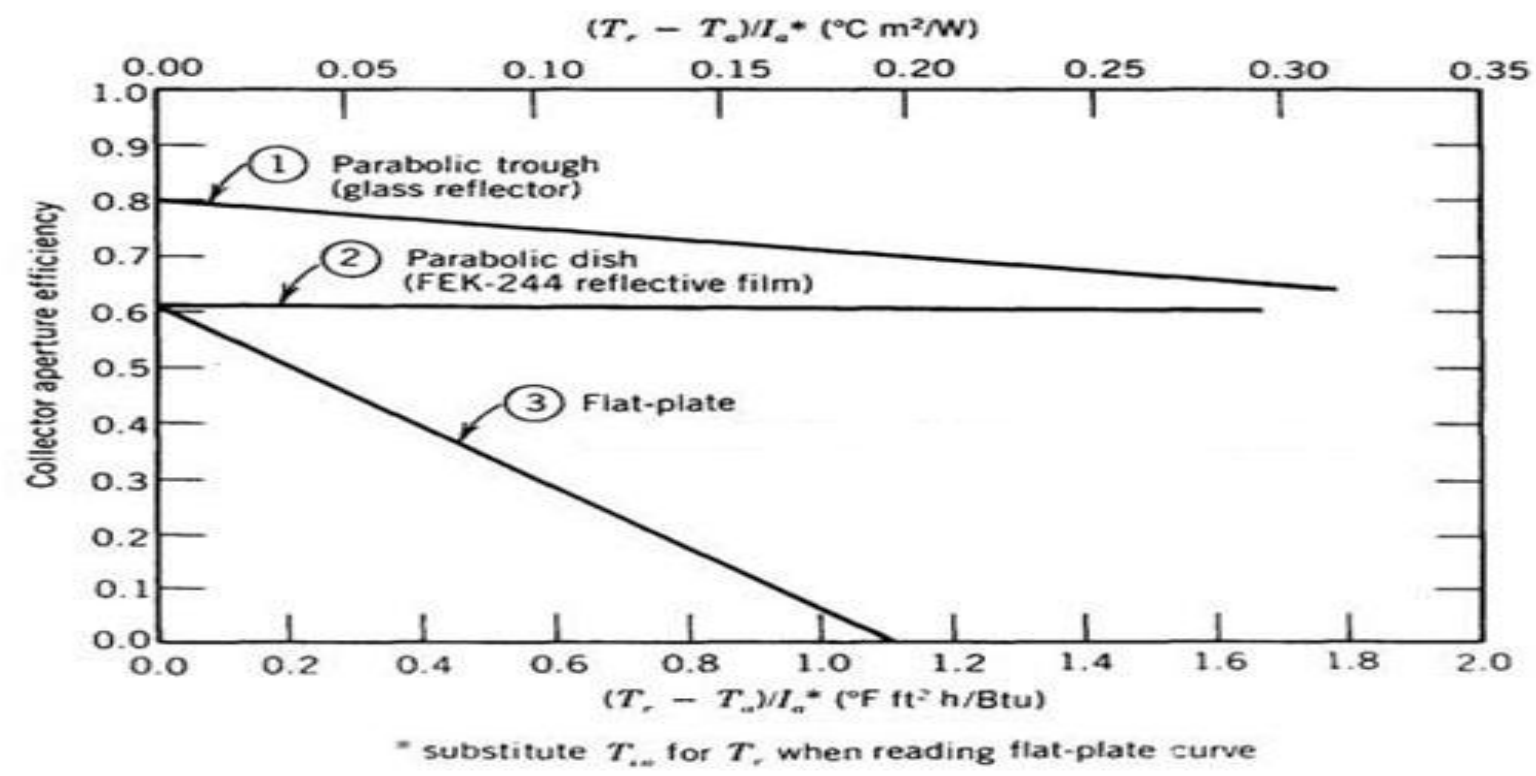

Fig: 1. Comparison of experimentally measured $\Delta \mathrm{T} / \mathrm{I}$ curves with flat-plate collector performance.

Mathematical expression for predicting the performance characteristics of solar paraboloidal dish type concentrating collector with reverse flat plate absorber of rectangular shape have been derived. The concentrator receiver assembly is shown in Fig: 2. This arrangement takes advantage of easy intermittent tracking and suppression of convection heat losses to an appreciable extent as compared to other types. Some realistic assumptions were made to simplify the procedure for obtaining expressions for stagnation temperature $\left(\mathrm{T}_{\mathrm{ps}}\right)$, Plate temperature $\left(T_{p}\right)$ and water temperature $\left(T_{w}\right)$ with respect to various input parameters ${ }^{[10]}$.

\section{Water Temperature $\left(\mathbf{T}_{\mathrm{w}}\right)$}

The net amount of radiant energy reaching the

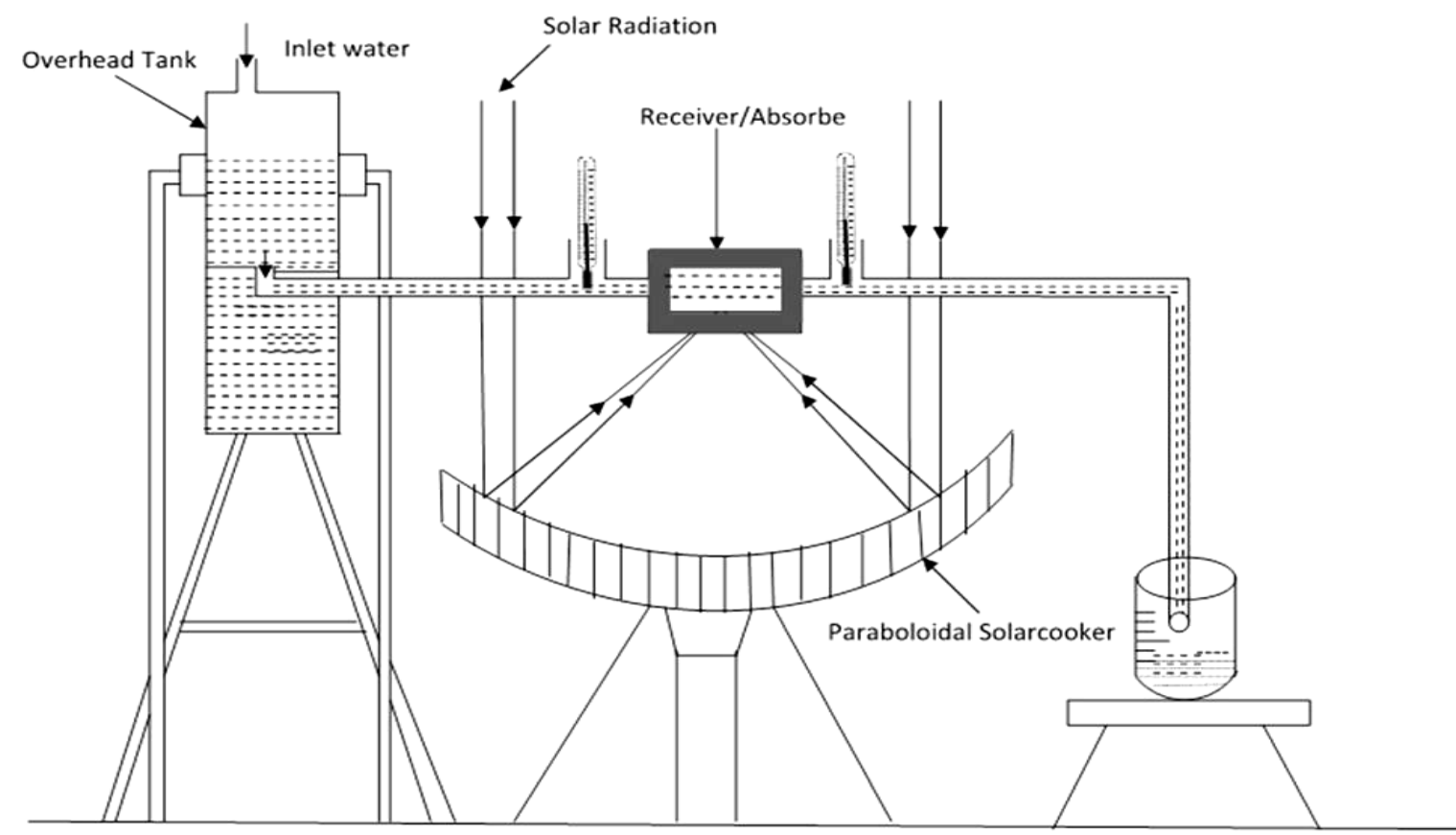

Fig: 2. An experimental setup of a solar paraboloidal dish type concentrating collector. elementary area of the receiver surface ${ }^{[6]}$ Fig. (1) will be $=C \eta_{0} I_{b} l d x$, Where, $\eta_{0}=$ Optical efficiency, $C=$ Concentration ratio, $I_{b}=$ Beam Radiation, $l=$ Breadth of the absorber, $d x=$ Elementary length of the absorber surface.

In the steady state condition, this energy may be balanced as follows:

$$
\begin{aligned}
& C \eta_{0} I_{b} l d x=m_{w} C_{w} d T_{w}+U_{L} l\left(T_{p}-T_{a}\right) d x \\
& \ldots \ldots \ldots \ldots \ldots \ldots \ldots \ldots \ldots \ldots \ldots \ldots \ldots \ldots \ldots \ldots \ldots \ldots \\
& \therefore \\
& T_{p} d x=\frac{C \eta_{0} I_{b} l d x}{U_{L} l}-\frac{\tilde{m}_{w} C_{w} d T_{w}}{U_{L} l}+T_{a} d x
\end{aligned}
$$

The amount of heat transferred to the heat transfer fluid may be written as,

$$
\dot{m}_{w} C_{w} d T_{w}=U_{L} l_{i}\left(T_{p}-T_{a}\right) d x
$$


$\therefore T_{p} d x=C \eta_{0} I_{b} \frac{\tilde{m}_{w} C_{W} d T_{W}}{v_{L} l_{\hat{i}}}+T_{w} d x$

From the equations (ii) \& (iv), we get

$\left(\frac{C \eta_{0} I_{b}}{v_{L}}+T_{a}\right) d x=\dot{m}_{w} C_{w}\left(\frac{1}{v_{L} l}+\frac{1}{v_{L} l_{L}}\right) d T_{w}+T_{w} d x$

This equation is of the form

$A d x=B d T_{w}+T_{w} \Rightarrow d x=\frac{B d T_{w}}{A-T_{w}}$

Where, $A=\frac{C \eta_{0} I_{b}}{U_{L}}+T_{a}$, And

$B=\dot{m}_{w} C_{w}\left(\frac{1}{v_{L} l}+\frac{1}{v_{L} l_{i}}\right)$.

Now, integrating equation (vi) and putting the boundary condition at $x=0, T_{w}=T_{w i}$, we get water temperature,

$T_{w}=A-\left(A-T_{w i}\right) \exp \left(\frac{-\mathbf{x}}{\mathrm{B}}\right)$

Substituting the values of A \& B in equation (vii), we get

$T_{w}=\left(\frac{c \eta_{0} I_{b}}{U_{L}}+T_{a}\right)-\left(\frac{c \eta_{0} I_{b}}{U_{L}}+T_{a}-T_{w i}\right) \exp \left[\frac{-x}{\dot{m}_{w} c_{w}\left(\frac{1}{U_{L} I^{2}}+\frac{1}{U_{L} L_{i}}\right)}\right]$

Plate Temperature $\left(T_{p}\right)$

From the equation (iv), we may further proceed to obtain the expression for plate temperature [7],

$\frac{\tilde{m}_{w} C_{w}}{U_{L} l_{i}} \cdot \frac{d T_{w}}{d x}+T_{w}$

.........(ix)

Now differentiating equation (ix), we get

$\frac{d T_{w w}}{d x}=\frac{U_{L} l \cdot U_{L} l_{i}}{m_{w} c_{w w}\left(U_{L} l+U_{L} l_{i}\right)} \cdot\left(\frac{c \eta_{0} l_{b}}{U_{L}}+T_{a}-T_{w i}\right) \cdot \exp \left[\frac{-x}{\grave{m}_{w w} c_{w w}\left(\frac{1}{U_{L} L}+\frac{1}{U_{L} l_{i}}\right)}\right]$

Now putting the value of $\frac{d T_{w}}{d x}$ in equation (ix), we get the expression for plate temperature

$T_{p}=\frac{v_{L} l}{U_{L} l+U_{L} l_{i}} \exp \left[\frac{-x}{\dot{m}_{w} C_{w}\left(\frac{1}{U_{L} I^{l}}+\frac{1}{U_{L} l_{\mathrm{i}}}\right)}\right]+T_{w} \ldots$

\section{Stagnation Temperature $\left(T_{p s}\right)$}

If there is no flow of heat transfer fluid through the absorber channel and the beam radiation is uniformly distributed over the absorber ${ }^{[8]}$, the energy balance on the absorber surface may be written as,

$$
\begin{aligned}
& C \eta_{0} I_{x}=\dot{m}_{p s} C_{p s} \frac{d T_{p s}}{d t}+U_{L} l x\left(T_{p s}-T_{a}\right) \\
& \ldots \ldots \ldots \ldots \ldots \ldots \ldots \ldots \ldots \ldots \ldots \ldots \ldots \ldots \ldots \ldots \ldots \ldots \ldots \ldots \ldots \ldots \ldots \ldots \ldots \ldots \ldots \\
& \text { Or, }
\end{aligned}
$$

Now, putting $\frac{U_{L} l x}{\dot{m}_{p s} c_{p s}}=A, \frac{U_{L} l x}{\dot{m}_{p s} c_{p s}}=B$, $\frac{C \eta_{0 I_{b}}}{U_{L}}+K$, Then, $\frac{A}{B}=K$

Now substituting the values in equation (xiii) we get,

$$
\begin{aligned}
& \frac{d T_{p s}}{d t}=A-B T_{p s} \\
& \Rightarrow \frac{d T_{p s}}{A-B T_{p s}}=d t
\end{aligned}
$$

Integrating both sides and putting the boundary condition

$$
\begin{gathered}
\int_{T_{p i}}^{T_{p s}} \frac{d T_{p s}}{A-B T_{p s}}=\int_{0}^{t} d t \\
\Rightarrow>\left[-\frac{1}{B} \ln \left(A-B T_{p s}\right)\right]=t \\
\Rightarrow> \\
A-B T_{p s}=\left(A-B T_{p i}\right) \exp (-B t) \\
T_{p s}=\frac{A}{B}-\left(\frac{A}{B}-T_{p i}\right) \exp (-B t)
\end{gathered}
$$

Substituting the values for $\mathrm{K} \& \mathrm{~B}$, we get expression for stagnation temperature

$T_{p s}=\left(\frac{C \eta_{0 I_{b}}}{v_{L}}+T_{a}\right)-\left(\frac{C_{\eta_{0 l_{b}}}}{v_{L}}+T_{a}-T_{p i}\right) \exp \left(\frac{v_{L} l x}{\dot{m}_{p s} C_{p s}}\right)$

...............................(xiv)

Overall heat transfer co-efficient from

receiver surface to water $(u)$ :

From fig: 1 let us suppose that,

$T_{p(x)}=$ Outer surface temperature of the receiver,

$T_{p i(x)}=$ Inner surface temperature of the receiver,

$T_{w(x)}=$ Water temperature at equilibrium,

Heat transferred from $T_{p(x)}$ to $T_{p i(x)}$ will be given by Prescott (1940) ${ }^{[7]}$,

$q_{1}=$

$\frac{K_{m} l\left(T_{p}-T_{p i}\right) d x}{\Delta m}$

Where, $\Delta m$ is the thickness and $K_{m}$ thermal conductivity of the absorber plate.

Heat converted from inner surface of wall to water is given by,

$q_{2}=2 h_{w}\left(l_{i}+b\right)\left(T_{p i}-T_{w}\right) d x$

Where $\mathrm{h}_{\mathrm{w}}$ is the heat transfer coefficient from inner surface to water .Heat transferred from outer surface to water will be given by,

$q_{3}=U l_{i}\left(T_{p}-T_{w}\right) d x$

$\Rightarrow q_{3}=U l_{i}\left\{T_{p}-T_{p i}+\left(T_{p i}-T_{w}\right)\right\} d x$

........................................ (xvii)

Now, from equation (xv) and (xvii), we get

$T_{p}-T_{p i}=\frac{q_{1} d m}{K_{m} l d x}$ and

$T_{p i}-T_{w}=\frac{q_{z}}{2 h_{w}\left(l_{i}+b\right) d x}$

Putting these values in equation (xvii) and assuming

$q_{1}=q_{2}=q_{3}$

One can get the expression for heat transfer

coefficient from surface to water $(\mathrm{U})$, 
$\mathrm{U}=\frac{\frac{\mathrm{I}}{\mathrm{I}_{\mathrm{i}}}}{\frac{T_{\mathrm{m}}}{K_{\mathrm{m}}}+\frac{\mathrm{l}}{\mathrm{n} h_{\mathrm{w}}\left(\mathrm{I}_{\mathrm{i}}+b\right)}}$

Overall heat loss co-efficient from receiver surface to surrounding $\left(\mathbf{u}_{\mathrm{l}}\right)$

$T_{g i}=$ Inner surface temperature of glass cover,

$T_{g \circ}=$ Outer surface temperature of glass cover,

Heat loss to the surrounding from the receiver surface,

$q_{1}=U_{L}\left(T_{p}-T_{a}\right) l d x$

$q_{1}=U_{L} l\left[\left(T_{p}-T_{g i}\right)+\left(T_{g i}-T_{g o}\right)+\left(T_{g o}-T_{a}\right) d x\right]$

Heat transferred from receiver surface to inner surface of glass by convention

$q_{2}=$

$h_{a 1} l\left(T_{p}-T_{g i}\right) d x$

Heat conducted through the glass wall

$q_{3}=\frac{K_{g} l\left(T_{g i}-T_{g o}\right) d x}{\Delta g}$

(xxi)

Where $K_{g}$ and $\Delta g$ is the thermal conductivity and thickness of the glass.

Again heat loss to the ambient from the outer surface of glass,

$q_{4}=h_{a 2} l$

$\left(T_{g o}-T_{a}\right) d x$ (xxii)

From equation (xx),(xxi) and (xxii),

$T_{p}-T_{g i}=\frac{q_{z}}{h_{a 1} l d x}$

$T_{g i}-T_{g 0}=\frac{q_{\mathrm{g} \Delta g}}{K_{g} l d x}$

$T_{g o}-T_{a}=\frac{q_{4}}{h_{a 2} l d x}$

Putting these values in equation (xix) and assuming

that $q_{1}=q_{2}=q_{3}=q_{4}$

One can get an expression for overall heat loss coefficient as

$U_{L}=\left(\frac{1}{h_{a 1}}+\frac{\Delta g}{K_{g}}+\frac{1}{h_{a n}}\right)^{-1}$

Where, $h_{a 1}$ and $h_{a 2}$ are inside and outside convection heat loss coefficients.

\section{RESULTS \& DISCUSSION}

Fig: 3. shows the comparative variation of plate and water temperature with beam radiation. It is seen that at lower insolation level, the plate and water temperature difference is narrower than that at higher insolation. It is also appears that at zero insolation the plate \& water will be almost at the same temperature. The reason is obvious from the fact that with the increase of insolation, the plate can absorb energy more quickly than the water can through the plate where as overall heat loss factor $\left(\mathrm{U}_{2}\right)$ increases at the elevated temperature. This results in the difference of temperature in the plate $\&$ water.

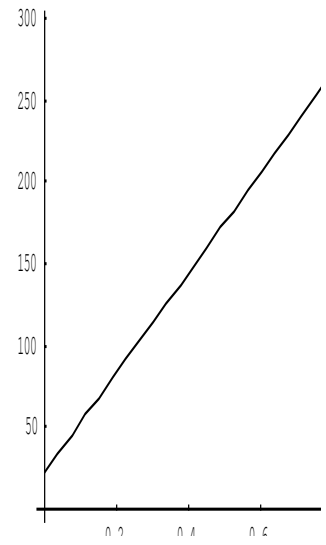

(a) Plate temperature vs. insolation

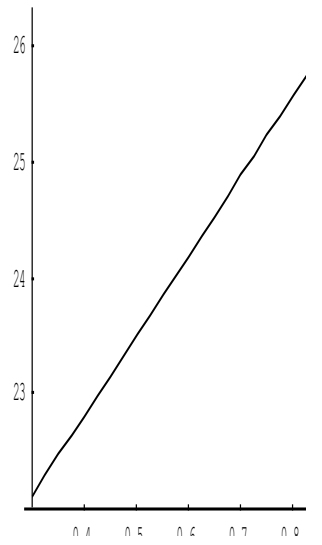

(b) Water temperature vs. insolation
Fig: 3. Variation of (a) plate and (b) water temperature with beam radiation

The variation of plate and water temperature with mass flow rate of heat transfer fluid is shown in fig: 4. It is seen that the temperature decreases is initially at a faster rate and then settles down approaching the ambient temperature. With the increase in mass flow rate the operating temperature decreases. As expected the system efficiency increases with decrease in operating temperature when $\mathrm{U}_{\mathrm{L}}$ is less than that are higher operating temperatures.

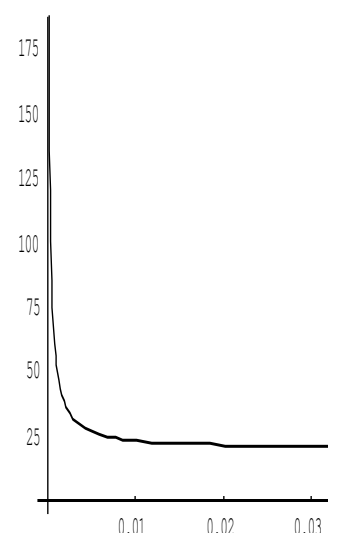

(a) Water temperature vs. mass flow rate

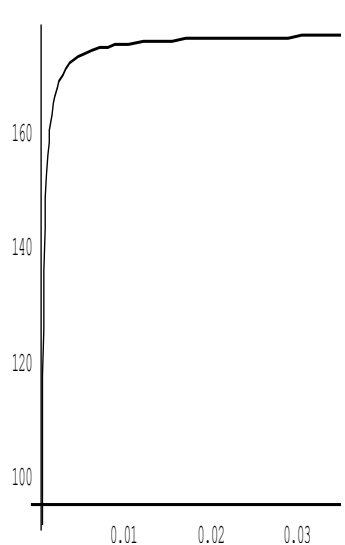

(b) Plate temperature vs. mass flow rate
Fig: 4. The variation of (a) plate and (b) water temperature with mass flow rate

The variation of plate and water temperature difference with the length of the rectangular channel absorber is shown in Fig: 5. It is seen from the figure that with the increasing length the plate \& water temperature difference tends to zero meaning there by that at the end of a long absorber channel, the plate and water temperature become the same. As expected the plate \& water temperature increases more or less exponentially with the length of the absorber channel. 


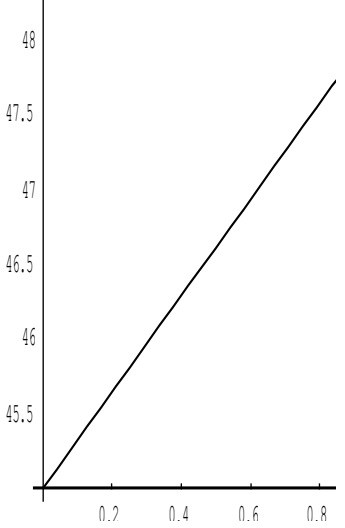

(a) Plate temperature vs length

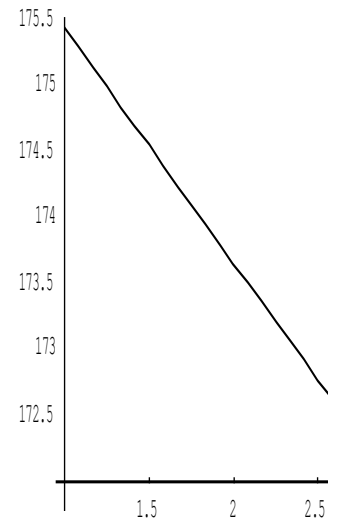

(b) Water temperature vs length
Fig: 5. The variation of (a) plate and (b) water temperature difference with the length

The effect of variation of mass flow rate of heat transfer fluid on the efficiency of the CR- system is shown in Fig: 6. It is observed that the mass flow rate increases the efficiency increases. From the figure it is observed that about $8 \%$ increase in efficiency occurs when mass flow rate is varied from .001 $\mathrm{kg} / \mathrm{sec}$ to $0.007 \mathrm{~kg} / \mathrm{sec}$. No appreciable change is observed during the variation between $0.007 \mathrm{~kg} / \mathrm{sec}-$ $0.017 \mathrm{~kg} / \mathrm{sec}$ onward.

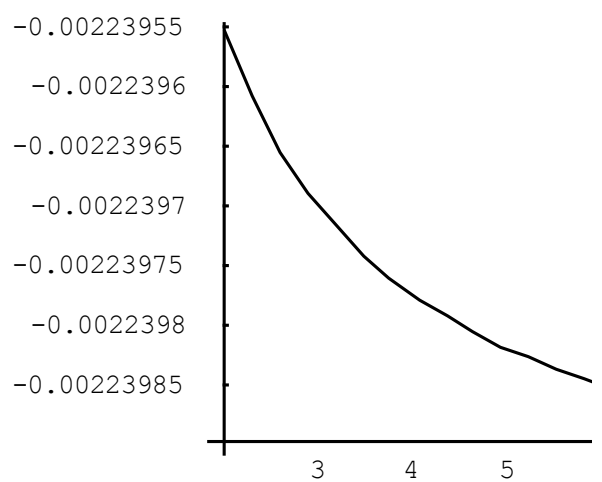

Fig: 6. Variation of mass flow rate of heat transfer fluid on the efficiency of the CR-system.

The variation of the plate and water temperature with concentration ratio is shown in Fig: 7. It is shown that the plate \& water temperature difference increases with the increase in concentration ratio, the plate can absorb energy quicker that the heat transfer fluid can do through the absorber plate after incurring different sorts of heat losses. This leads to the widening of plate $\&$ water temperature difference with the increase in the concentration ratio.

The variation of stagnation temperature with the hour of the day is shown in Fig: 8. It is seen that as time goes on the stagnation temperature starts increasing almost linearly and then after sufficient time span around solar noon, in tends to saturate at certain temperature when insolation level attains the peak value. The variation of temperature many attribute to the fact that the insolation varies with the time of the day

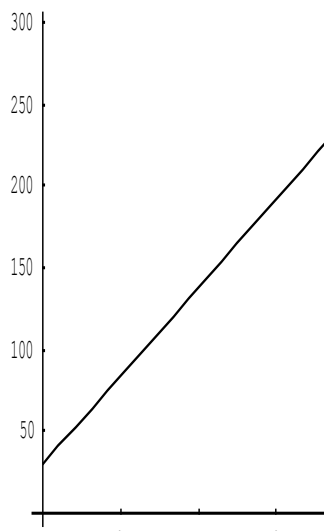

(a) Plate temperature vs concentration ratio

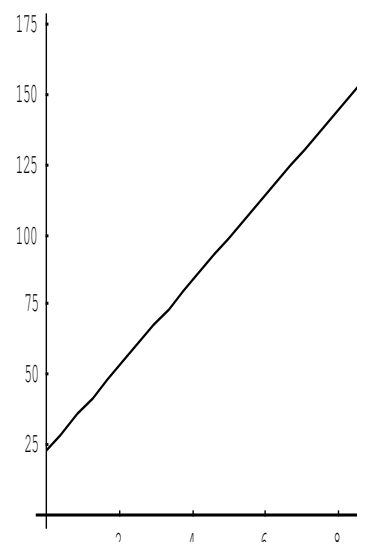

(b) Water temperature vs. concentration
Fig: 7. Variation of the (a) plate and (b) water temperature with concentration ratio

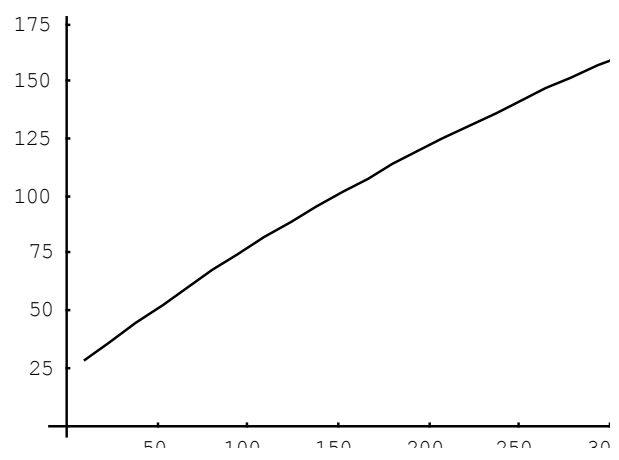

Fig: 8. Variation of stagnation temperature with the hour of the day

The variation of stagnation temperature with the length of the absorber is shown in Fig: 9. It is observed that with the increase of the observer channel, the stagnation temperature rises sharply and almost linearly at the beginning and then settles down exponentially at its saturation level. The computed values of the performance characteristics for a particular mass flow rate, insolation and ambient temperature are shown in appendix for comparison with measured values for both selective $\&$ non-selective coatings.

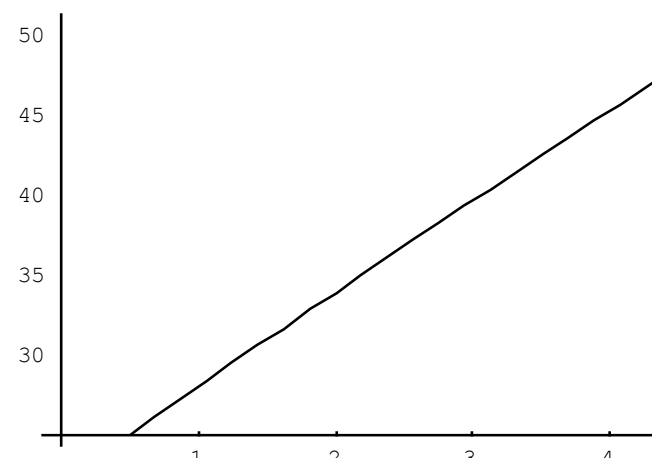

Fig: 9. Variation of stagnation temperature with the length of the absorber 


\section{CONCLUSION}

There are different kinds of solar concentrating collectors for practical utilization in different cases like solar thermal steam production and distillation, solar candle production, solar gur production, solar soap production, solar paddy boiling, solar biscuits production, solar chocolate production, solar salt production etc. Although this work is done for paraboloidal dish type concentrating collector, it will also help to design and fabricate other any type of concentrating collectors for practical utilization under the climatic condition of Bangladesh.

\section{ACKNOWLEDGEMENT}

The authors sincerely thanks to the Solar Park, Department of Physics, Jagannath University for providing facilities to do this research.

\section{REFERENCES}

1. Davis JA and McKay DC (1982). Estimating Solar Irradiance and components. Solar Energy. 29(5):41-44

2. Frohlich C (1979). Contemporary measures of the solar constant in the solar output and its variation. Ass. Uni. Pre. Bld. 8(7): 220-225
3. Gariepy J (1980). Estimation of global solar radiation. Int. Rep. Ser. Meterol. 3(2): 31-33

4. Gopinath KK (1988). A simple method for predicting global solar radiation on a horizontal surface. Solar and Wind Technol. 5(3): 81-85

5. Kilic A and Ozturk A (1983). Solar Energy. Kipas Distribution. Istanbul, Turkish. 6(4): 76-83

6. Page JK (1961). The estimation of monthly mean values of daily total short wave radiation on vertical and inclined surface from sunshine records for latitudes $40 \mathrm{~N}-40 \mathrm{~S}$. Proc. UN Conf. on New Sources of Energy 4:378.

7. Prescott JA (1940). Evaporation from a water surface in relation to solar radiation. Trans. Roy Soc. Aust. 64: 114-148.

8. Revfein KJA (1983). An interpretation of the coefficients of the Angstrom Equation. Solar Energy. 31: 415

9. Bean JR (1995). Technical Status of the Dish/Stirling Program. IECEC. 15: 110-117

10. Beninga K (1997). Performance Results for the SAIC/STM Prototype Dish/Stirling System. Proceedings of the ASME International Solar Energy Conference, Washington, D.C. 